\title{
Report of Workshop on Advanced Methods and Models for Appearance of Coatings and Coated Objects
}

National Institute of Standards and Technology Gaithersburg, MD May 20, 1996

\author{
Mary E. McKnight \\ Jonathan W. Martin \\ Michael A. Galler \\ Building and Fire Research Laboratory \\ Fern Y. Hunt \\ Robert R. Lipman \\ Information Technology Laboratory \\ Theodore V. Vorburger \\ Manufacturing Engineering Laboratory \\ Ambler E. Thompson \\ Physics Laboratory
}

U.S. DEPARTMENT OF COMMERCE

Technology Administration

National Institute of Standards

and Technology

Gaithersburg, MD 20899-0001

\section{NIT}




\section{Report of Workshop on Advanced Methods and Models for Appearance of Coatings and Coated Objects}

National Institute of Standards and Technology Gaithersburg, MD May 20, 1996

\author{
Mary E. McKnight \\ Jonathan W. Martin \\ Michael A. Galler \\ Building and Fire Research Laboratory

\section{Fern Y. Hunt} \\ Robert R. Lipman \\ Information Technology Laboratory \\ Theodore V. Vorburger \\ Manufacturing Engineering Laboratory \\ Ambler E. Thompson \\ Physics Laboratory
}

U.S. DEPARTMENT OF COMMERCE

Technology Administration

National Institute of Standards

and Technology

Gaithersburg, MD 20899-0001

March 1997

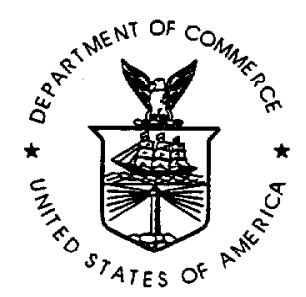

U.S. DEPARTMENT OF COMMERCE

William M. Daley, Secretary

TECHNOLOGY ADMINISTRATION

Mary L. Good, Under Secretary for Technology

NATIONAL INSTITUTE OF STANDARDS

AND TECHNOLOGY

Arati Prabhakar, Director 


\section{TABLE OF CONTENTS}

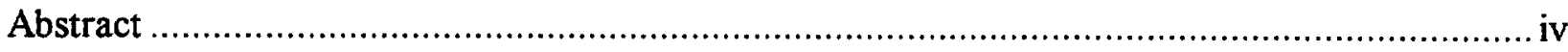

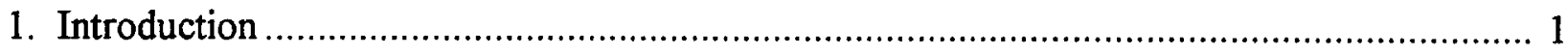

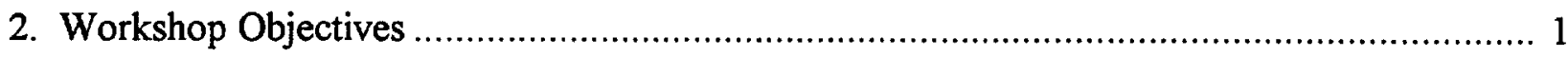

3. Abstracts of Industrial Presentations........................................................................ 2

Factors Contributing to Coating Appearance, Juergen Braun ........................................2

Appearance Measurements at DuPont: Past, Present and Future, Paul Tannenbaum, Richard Stafford, Arun Prakas, and Peter Jannson ..................................................... 3

Appearance Rendering, Holly Rushmeier ........................................................ 5

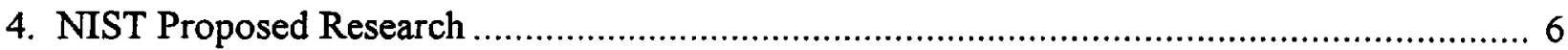

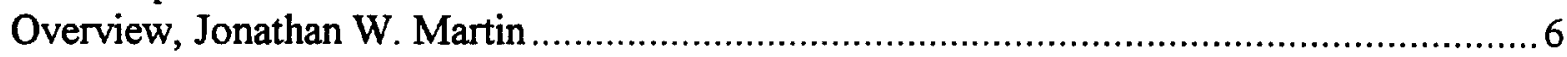

Simulation Modeling, Fern Y. Hunt .................................................................... 7

Appearance Measurements, Ambler Thompson ....................................................... 8

Surface-Morphology Measurements/Bidirectional Reflectance Distribution

Function (BRDF) Modeling, Theodore Vorburger, Egon Marx, Chris Evans, and W. Eric Byrd

5. Discussion: Issues and Recommendations ....................................................... 10

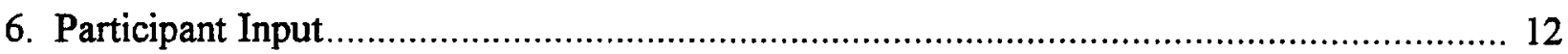

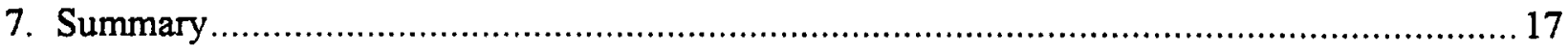

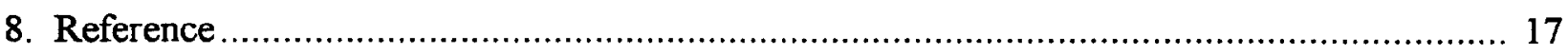

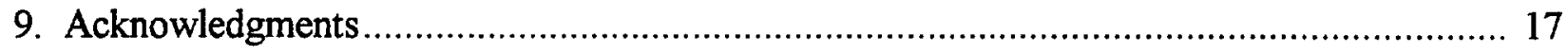

Appendices

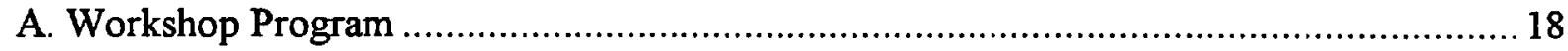

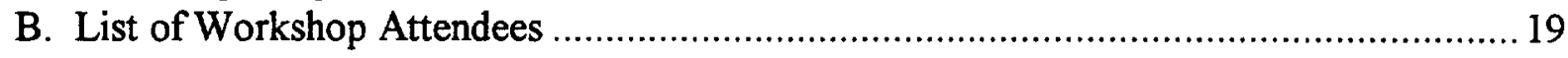




\section{Abstract}

Four NIST laboratories held a Workshop on Advanced Methods and Models for Appearance of Coatings and Coated Objects on May 20, 1996 to help NIST researchers better understand industry's needs. The four NIST laboratories are Building and Fire Research Laboratory (BFRL), Information Technology Laboratory (ITL), Manufacturing Engineering Laboratory (MEL) and Physics Laboratory (PL). Using coatings and coated products as a model system, industry representatives presented coating appearance-measurement issues, NIST researchers described their proposal for a systems approach to advance the science of appearance measurements, and, in an open forum discussion, workshop attendees provided feedback on the ideas presented and additional recommendations.

Keywords: appearance, bidirectional reflectance distribution function, BRDF, building technology, coatings, gonio-apparent, measurement, modeling, paints 


\section{INTRODUCTION}

The appearance (color, gloss, texture) of an object greatly influences a customer's appreciation of the quality of the object. Further, as manufacturers demonstrate their ability to provide objects having improved appearance properties, as well as exciting new ones, customer expectations for appearance quality increase. To enhance the development and implementation of new products and processes, it is essential that industries have the physical tools necessary to accurately quantify the appearance of their products, and the modeling capabilities to predict the appearance of objects based on their formulation and manufacturing processes.

Current appearance metrology is almost exclusively based on specular and colorimetric measurements. This has led to a host of specialized metrics - e.g., at least ten for "gloss" alone - that are useful in monitoring the day-to-day quality of a product, such as determining whether the paper produced today is as shiny as that produced yesterday. However, these metrics are inadequate for many current requirements including 1) describing metallic and pearlescent coatings which change appearance with angle of viewing and angle of illumination, 2) characterizing texture, 3) predicting the appearance of a finished product from the coating constituents, and 4) predicting the appearance of a coating as the product ages.

Needs for new or improved characterization procedures, metrics, standards, and tools have been recognized by the industry for some time. This is illustrated by recommendations in a recent report by the Council on Optical Radiation Measurements (CORM). ${ }^{1}$ The recommendations include establishing a national appearance measurement laboratory program at NIST that would address a variety of appearance attributes, including gloss, distinctness of image, orange peel, texture, sheen, translucency, and contrast. The Council further recommends that this effort be supported by developing a system of standard reference materials for these and other appearance attributes.

To help NIST researchers better understand industry's needs, four NIST laboratories held a Workshop on Advanced Methods and Models for Appearance of Coatings and Coated Objects on May 20, 1996. The four NIST laboratories are Building and Fire Research Laboratory (BFRL), Information Technology Laboratory (ITL), Manufacturing Engineering Laboratory (MEL) and Physics Laboratory (PL). Using coatings and coated products as a model system, industry representatives presented specific coating appearance measurement issues, NIST researchers described their proposal for a systems approach to advance the science of appearance measurements, and, in an open forum discussion, workshop attendees provided feedback on the ideas presented and additional recommendations.

\section{WORKSHOP OBJECTIVES}

The Workshop was organized with three objectives:

(1) To identify industry's needs for new appearance measurement methods, 
(2) To propose a program to meet industry's needs and define what NIST could and should do to help meet the needs, and

(3) To decide whether an industrial panel should be established to collaborate with NIST researchers in prioritizing research and advancing appearance methodologies and, if so, to initiate efforts to establish the panel.

The workshop was organized into three sessions: presentations by industry representatives, presentations by NIST researchers, and a panel discussion. The sessions were designed to identify common industrial problems in the area of coating appearance, to present a NIST proposal to advance methods and models for characterizing appearance, and to foster open communication among interested industrial, academic, and governmental groups.

\section{ABSTRACTS OF INDUSTRIAL PRESENTATIONS}

\section{Factors Contributing to Coating Appearance by Juergen Braun, Pigments and Coatings Technologies}

The appearance of man-made products has changed slowly over time as new pigments have become available. The evolution of the colors of the settings of most human activities is passing with hardly a notice. For a millennia, man has been surrounded by shades of gray and earth, the colors of dirt, dust, decay, ashes and soot. Although the wealthy gained access to some more lively colors provided by precious stones, white marble, noble metals and some dyes, it was not until modern times that gray was replaced by materials made with photolytically stable white and colored pigments, made possible by advances in pigment technology. For example, most automobiles were black or dark colored until the 1930 s because light colors were not durable enough to use on objects exposed to sunlight.

Appearance properties (described by the terms shown in Fig. 1) of most manufactured objects depend on pigments. The requirements of pigments include optical characteristics, safety, durability, and affordability. Extreme optical characteristics are required. For example, of the billions of chemical compounds, only a few have a refractive index high enough to serve as a white pigment. Colored pigments must have an extreme, wavelength-specific light absorption. A black pigment must have total light absorption. Safety during manufacture, application, and use is an additional concern. Pigments may be required to withstand the effects of UV radiation, water, oxygen, elevated temperatures, and environmental assaults by acids and alkalis. Cost is also an issue. Pigment prices vary from $\$ 0.05$ per kilogram for mined mineral pigments, to $\$ .50$ per kilogram for white and black pigments, and to $\$ 5$ - $\$ 50$ per kilogram for some color and special effect pigments.

The human environment is continually becoming more colorful. The language of appearance recognizes the impact of appearance on our emotions. New terms are being used to describe products made with new pigments, such as dazzle, vivid, glitter, and sparkle. Pigment technology is meeting the demands for changes in the appearance of products and continues to serve a subtle dimension of our well-being. 


\begin{tabular}{|ll||ll|}
\hline \multicolumn{4}{|l|}{ The Words of Appearance } \\
\hline & & & \\
\hline sheen & shine & dull & gray \\
polish & luster & drab & dark \\
bright & shimmer & lack-luster & bleak \\
light & bright & dingy & leaden \\
vivid & radiant & somber & hazy \\
glamorous & gleam & sooty & muddy \\
glitter & dazzle & cloudy & dusky \\
gloss & colorful & & \\
sparkle & brilliant & & \\
& & & \\
\hline
\end{tabular}

Figure 1. Terms Describing Appearance (J. Braun)

\section{Appearance Measurements at DuPont: Past, Present and Future by Paul Tannenbaum, Richard Stafford, Arun Prakash, and Peter Jannson, E.I. DuPont de Nemours \& Co.}

Appearance is the total quality of what we perceive. Color, texture, luster, gloss, haze, sparkle, and roughness are examples of appearance attributes. The quality of many of the products DuPont markets is judged by combinations of these attributes. The rules for combining these attributes to create specific appearance properties, however, are not known. Many established DuPont product lines are sold specifically for their appearance value. Among these are automotive finishes, textile and carpet fibers, Corian $\otimes$, and colored Tedlar@. Other DuPont materials, such as composites, engineering polymers, white pigments, and printing supplies are used as components in customer products. These materials convey properties that indirectly affect end-use appearance. Taken together, the value of appearance represents substantial revenues and earnings. Small generic improvements in appearance understanding, measurement, and control can provide significant competitive advantage. DuPont has demonstrated this principle repeatedly in the appearance subfield of color and is currently expanding upon its colorbased activities by measuring process-dependent appearance attributes, improving the appearance assessment of current products, and developing new products having more desirable appearance.

The quantification of appearance involves a high degree of connectivity among the many subfields of science and technology and different businesses. The degree of complexity and the specific scientific disciplines that are required for business appearance solutions are illustrated in Fig 2. A partial listing of candidate appearance attributes is at the core of the diagram. Associated businesses are included as the outer shell. 


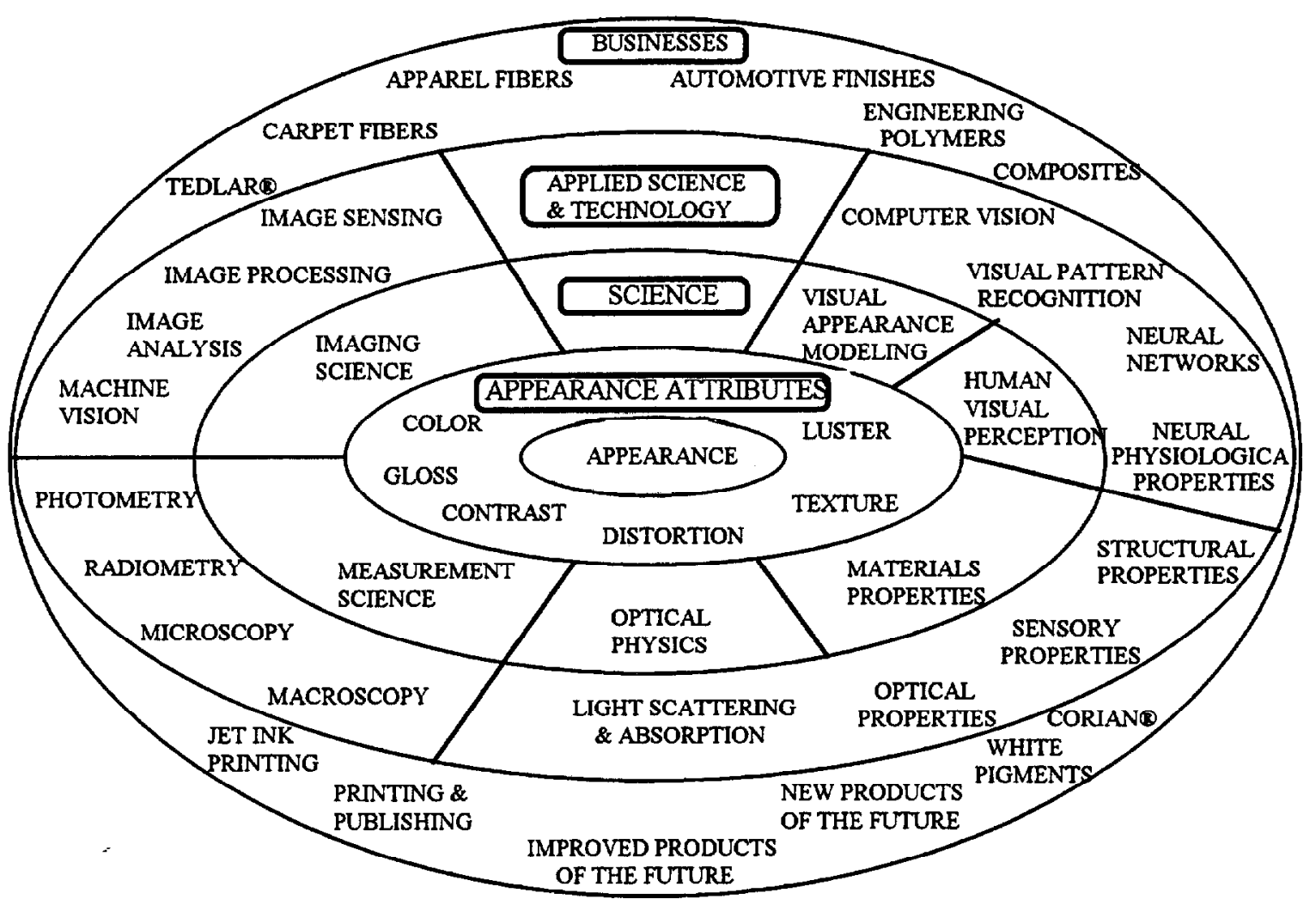

Figure 2. Connectivity of Areas and Groups Involved in Appearance Measurements (P. Tannenbaum, et al.)

Historically DuPont's first encounter with appearance came when Henry Ford asked the Company to develop a fast drying black lacquer. This ultimately led to colored automotive products and later, colored fibers which required quality control support. Hence, DuPont first developed the Colormaster colorimeter and, as technologies improved, the DuColor colorimeter to meet specific business needs. During the same period, C. D. Reilly created the cube root color coordinate system which later became the CIE Lab system for quantitatively specifying color. With the introduction of metallic flakes into automotive finishes, a new "arch" goniophotometer, with 32 calibrated detectors which covered a hemisphere, was developed and used to study the reflectance of metallic finishes, as well as pearlescent finishes, and to improve colorant formulation and shading. When reliable computer controlled electronic displays and projection systems became available, simulation and color difference assessment tools were also developed. In particular, one such device would project a car on a large screen from which color styling could be done. When a color was chosen, paint could be immediately obtained via a link to a formulation computer with computer controlled pumps for the colorants, mixing machines, etc.

Currently, DuPont has shifted its focus somewhat to include some of the spatial aspects of appearance. For example, the effect of textile and carpet fiber shape on light scattering and 
reflectance and how these properties impact the ultimate luster, glitter and dye yield of the final product has been modeled. A large and successful effort has also been conducted to the study of standard appearance measures such as distinctness of image (DOI), orange peel, gloss, haze and contrast, in terms of imaging rather than flux techniques, which utilize standard optical transfer function (OTF) methods in conjunction with Fourier analysis and, hence, a spatial frequency framework. The advantage of the latter is a unified approach with one instrument for the determination of all the above attributes and a direct link to spatial vision via the published spatial frequency response of the human observer. In this framework, the OTF curves serve a function analogous to reflectance curves in color and the visual OTF is similar to the y-bar-lambda weighting function so that the specifying equations look a lot like those used in colorimetry except that wavelength is replaced by spatial frequency. Other spatial approaches utilize image processing techniques in quantifying textures, patterns, smoothness, scratches and mar, and surface wear. Here, specialized lighting and carefully configured optical systems play a role equal to the software analysis in isolating the features of importance. Specialized lighting is often overlooked in off-the-shelf systems. Most recently, DuPont has begun to simulate color spatial patterns on calibrated color monitors and then print these images on paper with the color match based on some predetermined transformation. Success depends on the accuracy of the color models for the monitor and printer as well as the measurement and calibration techniques. For the relatively simple case of heathered carpet yarn, we can now get a printed output which looks identical to the finished carpet.

For the future, DuPont sees a continuation of the present approaches enhanced by new technologies, as it was for the past. In modeling, we hope to pursue textural appearance uniformity, perceptual neuroscience and color spatial vision. In instrumentation, portable image processing systems will bring the measurements to the places where they are needed and large area, high resolution color image capture devices will insure proper statistics for analysis of complex images. New image processing research will include color image segmentation and aggregation analysis, as well as product-process appearance relationships. Finally, it is compelling to pursue the newest computer based virtual reality in 3D-color to simulate all of DuPont's products, i.e., fill a virtual house with virtual paint, virtual carpet and upholstery etc.

\section{Appearance Rendering}

by Holly Rushmeier, IBM, T.J. Watson Laboratory

Over the past 15 years, there has been a great interest in computer graphics in generating realistic synthetic images. In particular, a lot of work has been done in developing algorithms for physically accurate images -- that is, images computed from numerical descriptions of a scene that accurately show what the scene would look like if it were built. This has been a computationally challenging problem, requiring the solution of the Fredholm integral equation of the second kind that governs the transport of visible light. Efficient solution methods have been developed. Given the BRDF (bidirectional reflectance distribution function) for each of the objects in a scene, a physically accurate image can be generated in a reasonable amount of time. This allows, for example, the simulation of the appearance of cars under different lighting conditions with different paints entirely or the aging patina on a copper statue on a computer for the purpose of evaluating various design proposals. Such simulations would currently use limited experimental BRDF data. 
Now the time has come to move on to developing improved methods for obtaining BRDF data and models to predict BRDF given the initial components of a coating and the weather conditions expected. This would allow computer graphics techniques to be used through the entire design process of a coated object -- from the original coating formulation to the final appearance of an object under service conditions.

\title{
4. NIST PROPOSED RESEARCH
}

\author{
Overview \\ by Jonathan W. Martin, Building and Fire Research Laboratory
}

A NIST proposal for a systems approach to advance the science of appearance measurements for organic coatings was presented. Organic coatings are proposed as the model system, but the methods developed here will have direct application to other coatings and surfaces. The goals of the proposed research are to:

- Develop advanced textural, spectral, and reflectance metrologies for quantifying light scattering from a coating and its constituents and use the resulting measurements to generate maps and validate physical models describing optical scattering from a coating and the relationship that the scattering maps have to the appearance of a coated object.

- Develop models for predicting changes in appearance of a coating as it ages from knowledge of its physical and chemical properties, constituents and initial appearance.

- Integrate measurements and models in making a virtual representation of the appearance of a coating system and changes in appearance with aging. This representation can be used as a design tool capable of accurately predicting the appearance properties of aged and unaged coated objects from the coating formulation.

Planned experimental and simulation efforts in four parallel research areas, as illustrated in Fig. 3, were described. These areas are coating formulation and film formation, microstructure of new and aged films, reflectance and appearance measurements and predictions, and the generation of virtual formulation and rendering strategies. Within each research area, experimental results will be compared with model predictions and differences in the results investigated. Information gained in one area will flow as input into other areas and will be used to design improved experiments in a feed-back looping process.

Linkages among the research areas were further described. The microstructure (pigment size distribution, pigment dispersion, surface morphology, etc.) of new and aged coatings will be experimentally characterized and used as input into mathematical models developed to predict the bidirectional reflectance distribution function (BRDF) for the coating and microstructure parameters. The BRDF of the coating will also be experimentally measured and compared with the predicted BRDF derived from the scattering and simulation models. Experimental 
microstructure data will also be used as input in models to simulate aging-caused changes in the appearance of coating films. To complete the virtual loop, images of coated objects will be rendered using BRDF data so that the rendered appearance of the objects can be compared with responses based on standard appearance measurements. In this way it was noted, researchers and engineers should be able to use parameterized mathematical models and computer rendering, coupled with advanced measurements, to assess the contribution of coating constituents to appearance and help design coatings with desired initial appearance and durability properties.

Advanced Methods and Models for Coating Appearance

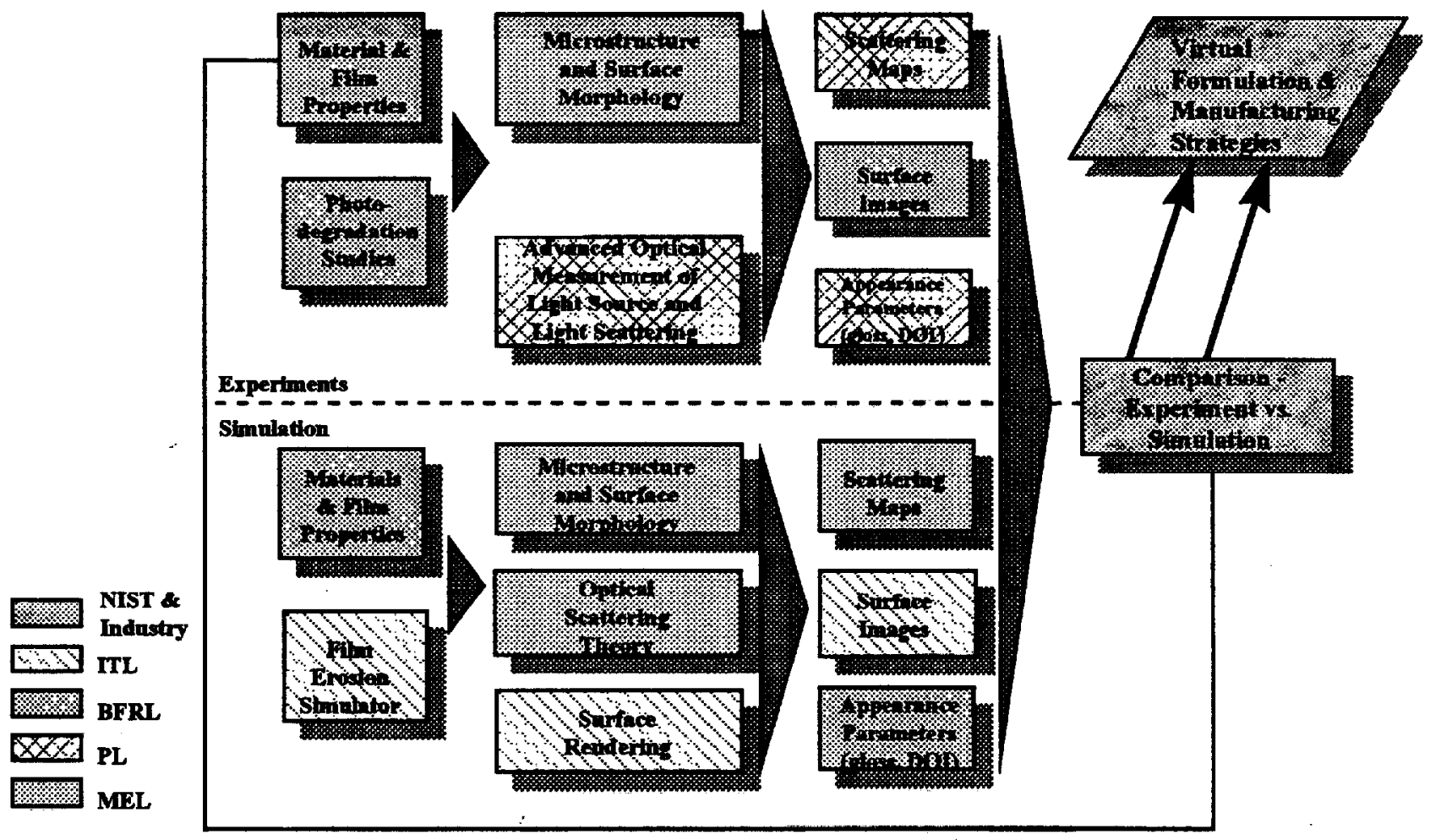

Figure 3. Schematsc of NIST's Proposed Research

\section{Simulation Modeling}

by Fern Y. Hunt, Information Technology Laboratory and Michael Galler, Building and Fire Research Laboratory

The role of the Information Technology Laboratory (ITL) in the proposed NIST effort, based on ITL's existing and developing expertise in the areas of modeling, computer simulation and computer graphics rendering, was presented. The goal of the ITL research is to contribute to the understanding of the microstructural basis for the appearance of coatings. Tools that will be developed to identify important parameters in the coating formulation process and their effect on appearance were described. These tools will allow designers and formulators to visualize the appearance of specified surfaces as part of a virtual formulation and manufacturing process as discussed by Dr. Rushmeier of the IBM T. J. Watson Laboratories. As an example of the kind of 
modeling and computer graphics visualization which will be developed, the results of a recent study of simulated gloss loss of coated surfaces exposed to ultraviolet light were presented. The computer simulation includes a display of the coating microstructure before and as the photodegradation process proceeds. The film consists of pixels depicting binder that erodes as ultraviolet radiation having adjustable strength and direction is absorbed. Embedded in the binder are collections of pixels representing pigment particles and other photo-stable additives. Pigment particle size distribution, shape and degree of dispersion or flocculation are adjustable, and are the principal model parameters of interest to paint formulators. The distributions of pigment particles are parameterized by point processes commonly used in spatial probability theory. The role that these parameters play in gloss loss of a weathered surface at various stages of the weathering process was investigated. As a first approximation, we used the first surface scattering theory of P. Beckmann, which relates the gloss to the surface roughness, and used it to determine gloss loss due to surface roughening. This hypothesis has been experimentally validated. The variables characterizing surface roughness are functions of the geometrical parameters of the surface and can be obtained by standard methods. We studied the dependence of these variables on pigment size distribution and dispersion in weathering simulations of coatings. Our results underscored the importance of small, well dispersed pigment particles in retaining gloss of pigmented films.

\section{Appearance Measurements}

by Ambler Thompson, Physics Laboratory

The metrological goals of the appearance project are to develop physical understanding and instrumentation for the complete characterization of color and appearance of coatings, resulting in advanced textural, spectral, and goniophotometric measurements for quantifying light interactions with coated surfaces. Procedures and instruments currently being used at NIST to measure reflectance properties of materials were described.

The reflectance of light from a coated surface is a complex physical problem, dependent on the angle of the incident light on the surface, the spectral distribution of the incident light, the physical properties of the sample, and the observing angle of the reflected light. The mathematical function which captures all of these parameters is the bidirectional reflectance distribution function (BRDF). Two BRDF instruments have been developed at NIST, both of which are capable of measuring the BRDF from coated surfaces. The measured BRDF can be compared with the model predictions leading to refinements in the model and augmentation in the design of future appearance instrumentation.

Reflectance is only one of the possible optical interactions of light with a coated surface; wavelength dependent absorbance results in a colored object. Fluorescence also occurs in some coatings (e.g. brighteners in paper and textiles and fluorescent coatings). Additional instruments will be built to completely characterize materials for all of these interactions. Our plans are for the instrumentation to have goniometric, spectral and imaging capabilities to accommodate material specific geometries. These instruments will be of sufficient sensitivity and accuracy to develop measurement transfer standards based on NIST's scales for the appearance industry. 


\section{Surface-Morphology Measurements/Bidirectional Reflectance Distribution Function (BRDF) Modeling \\ by Theodore Vorburger, Egon Marx, and Chris Evans, Manufacturing Engineering Laboratory and W. Eric. Byrd, Building and Fire Research Laboratory}

Techniques for measuring surface texture and subsurface morphology of coatings and proposed numerical methods for deriving the bidirectional reflectance distribution function (BRDF) from the surface measurements were described.

Several types of area profiling techniques can be used to measure a coating's surface texture. One of them, white light interferometric microscopy, will likely provide useful measurements of the subsurface structure, including the positions, sizes, and topography of subsurface pigment particles, including metallic and pearlescent particles. Another technique, confocal scanning optical microscopy, can provide measurements of the topography of the top surface of the coating as well the positions, sizes, and topography of subsurface pigment particles down to about $250 \mathrm{~nm}$ in size. The two techniques were described and examples of the measured coating morphology for both techniques were shown.

The proposed numerical approach to derive BRDF from the measured coating morphology is based on rigorous electromagnetic theory. A statistical model for the light scattered from the coating will be built from a series of elementary calculations of the light scattered from a single particle in a dielectric binder using integral equations equivalent to Maxwell's equations. The statistical model will take into account the roughness of the dielectric surface and the distribution of the particles in size and position. We have already developed computer codes to calculate rigorously the scattered field from a rough perfect conductor, a rough dielectric interface, and two neighboring dielectric spheres. Additional codes will be developed for a sphere in a rough dielectric layer and a sphere in a rough interface. Then the interaction of the light with the surface and the distribution of particles in the coating will be developed by summing the scattered light intensities from each interaction. The validity of this approximation will be evaluated by performing a rigorous calculation for light scattered from a small number of particles and comparing this result with that obtained by adding the intensities of the scattering from each of the particles.

Once an accurate model for scattering from coatings is developed, the results can be used as input BRDFs for surface image renderings and numerical estimates of appearance parameters from measurements of the surface topography. This method will avoid the necessity of measuring BRDF for each type of surface to be rendered. 


\section{DISCUSSION: BRIEF SUMMARY OF ISSUES AND RECOMMENDATIONS}

The presentations were followed by an informal open discussion period. Many issues and topics were addressed. To summarize the discussions for this report, the issues were grouped into four categories and broad recommendations were prepared based on suggestions and recommendations voiced during the discussion.

\section{METRICS AND MODELS}

Issue 1. The coatings, textile, paper and other industries have common appearance-related problems. From the measurement and modeling standpoints, there are definite end-points to strive for, such as developing capabilities for adequately measuring gloss, texture, and color, and relating models and microstructure to bidirectional reflectance distribution functions (BRDF). In addition to the major research and development efforts needed in the coatings industry, there will likely be needs for different appearance measurements and modeling in other industries.

Recommendation: University, industry and government working groups, in concert with supporting agencies (such as NIST) should address all aspects of appearance, including texture that will benefit the industries. This work should encompass image renderings of surfaces having complex reflectance properties, appropriate measurement instruments, models for predicting reflectance of surfaces from coating formulation, and models for aging of coatings.

Issue 2. With so many different color and appearance models and approaches available or being discussed, some form of standardization of the data must be developed. On a practical level, this means, "What data are needed to adequately describe reflectance properties and how should they be formatted so that the information is easily transferred from person to person?"

Recommendation: Develop standards for the description of color and appearance phenomena, taking into account existing processes and procedures, and industry-standard software tools.

Issue 3. The utility of standards and physical metrics in industrial processes and for research is clear, but the problem must still be bounded. Not only must measurements and models be developed that can be used by the interested communities, but some means of evaluating those models based on human perception must be developed. Implicit in this need are questions about the usefulness of existing appearance metrics, and the relationships between physical models and human vision models.

Recommendation: To evaluate and judge the efficacy of color and appearance models, interested parties should work together to develop metrics. For example, objective image quality metrics may be available from research institutions that are already heavily engaged in related work. NASA's Ames Research Center is an example. Modulation transfer function (MTF)-based quality measures may be suitable first steps. 


\section{TECHNOLOGY}

Issue 1. Measurements of appearance are often required in manufacturing plants and other locations remote from research or central laboratories. It is inconvenient to take physical samples from the location-of-choice for return to laboratories for measurements. The best solution would be to have measurement tools that can be used in situ.

Recommendation: To support in-situ measurements, portable devices should be developed to allow measurements in field or manufacturing environments.

Issue 2. As welcome as portable measuring devices would be, they may be difficult to design and build. Before any such instruments can be built, parameters for the design must arise from industrial needs. For example, pearlescent coatings might require that large surface areas be measured, and involve complex imaging systems, as well.

Recommendation: Industry working groups should be established to define the measurements that would be required to support their activities. Such definition would-of necessity-include the nature of the measurements, range of measured values, allowable uncertainties, and calibration, which itself requires the generation of standards.

\section{COMPUTATION}

Issue 1. Appearance rendering has significant potential for simulating the actual appearance of coated objects by generating images. Improvements in computer processor speeds and memory capabilities, rendering algorithms, and lower computer costs have made it possible to render images of scenes on the desktop. One obstacle to more accurate renderings is the lack of adequate reflectance data for objects coated with pearlescent and metallic coatings.

Recommendation: Appearance research should address representations for complex reflectances, appropriate measurement instruments, models for reflectance based on compound formulation, and models for aging of coatings. If such models and measurement techniques were available, it would allow examination of many different possible designs by combining coating formulation, product geometries, lighting conditions, and environmental effects entirely in simulation.

\section{MEASUREMENTS}

Issue 1. With computer-based capabilities to model reflectance distributions and simulate changes in surfaces due to weathering and aging, the question arises as to how best to relate models to reflectance measurements and microstructural characteristics. Some necessary parameters relative to appearance, e.g., surface roughness, can perhaps be derived from BRDF measurements. Additional procedures for characterizing other microstructural changes of coatings may also be needed to account for changes in the BRDF. 
Recommendation: Since traditional measurements take into account only the specular and near specular components of scattered light, development of new techniques, accessing diffuse components, should be addressed. In general, more and better measurements are needed, especially spectral goniophotometric measurements, in which incident and scattered light reflectance is varied over a wider range of directions.

Issue 2. Traditionally, measurements of BRDF use narrow light beams to illuminate the surface so spatial information is highly resolved. How to make effective use of BRDF as a spatially variable property is, as yet, an unresolved question. From a practical standpoint, such measurements are very alignment sensitive. It may be possible to use BRDF to determine specific appearance parameters. However, BRDF may be too labor-intensive and there may be alternative approaches. For example, the semiconductor industry routinely uses integrated scattering to scan for defects. This approach can address many samples per hour, and be automated to work $24 \mathrm{~h}$ a day.

Recommendation: While there may be alternative techniques, one must start somewhere, and $B R D F$ measurements are a good place to start. However, the details of carrying out BRDF measurements and using BRDF data need to be developed. Detailed descriptions of the utility of $B R D F$ vis-a-vis what industry wants, e.g., quality assurance metrics and standards, should be developed and provided.

\section{PARTICIPANT INPUT}

To provide participants with an opportunity to express specific ideas and thoughts and to provide NIST researchers with additional information, an input form was distributed. The responses are summarized below.

Questionnaire Responses

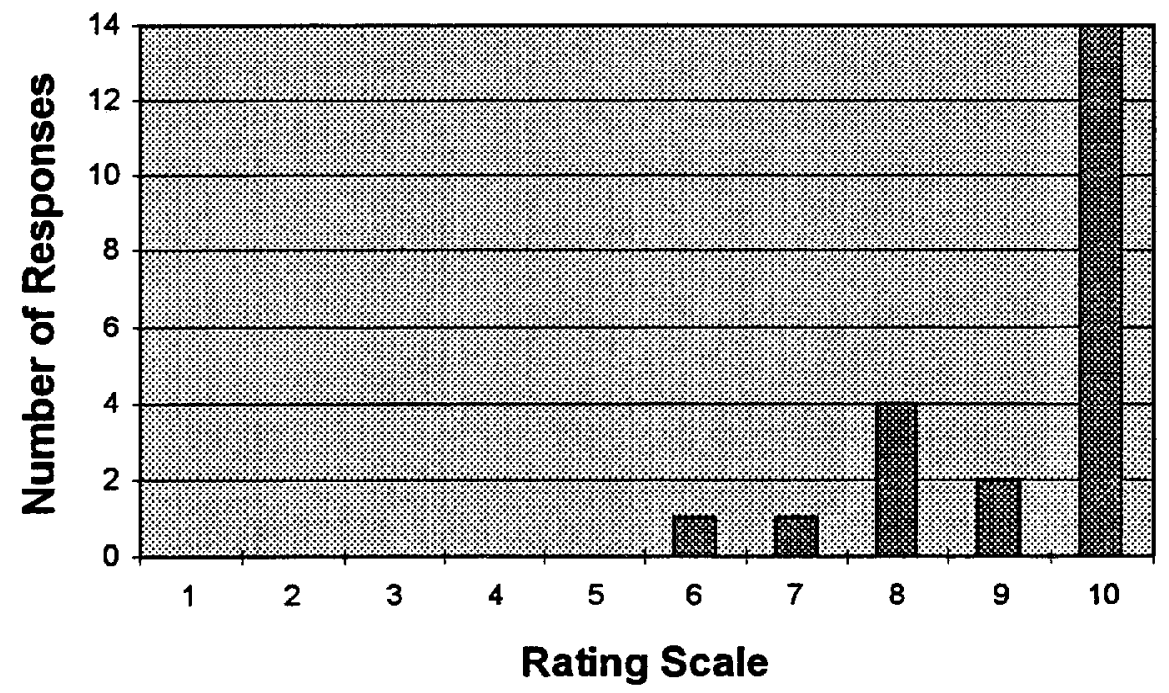

On a scale of 1 (not that important) to 10 (very important), how important are appearance measurements to your company? 
Questionnaire Responses, Continued

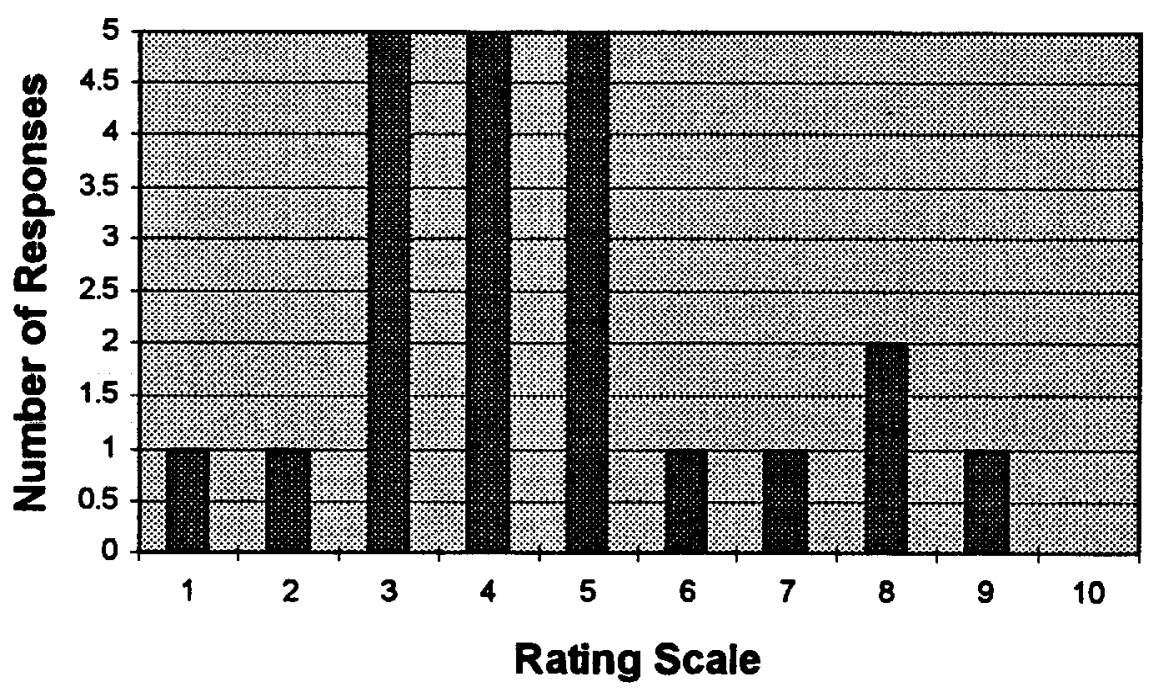

On a scale of 1 (need drastic improvement) to 10 (acceptable as is), how do you rate the current appearance measurements?

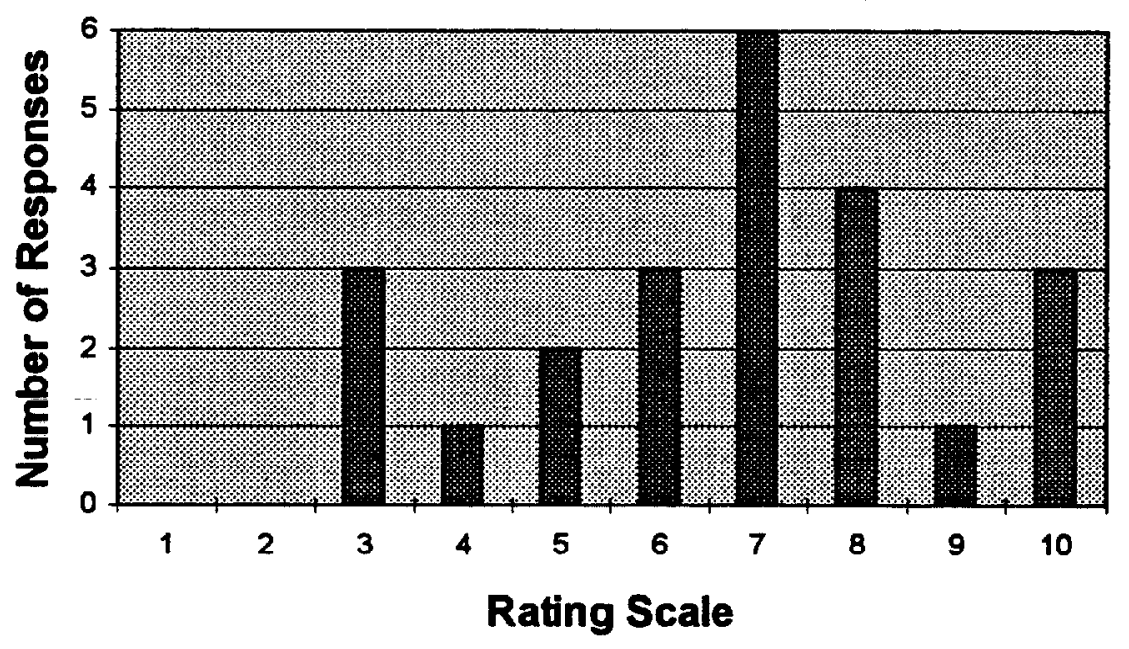

At this workshop, NIST proposed a project, "Advanced Methods and Models for Appearance of Coatings and Coated Objects." On a scale of 1 (not an advance) to 10 (possibly a major advance), how do you view NIST's proposal? 
Questionnaire Responses, Continued

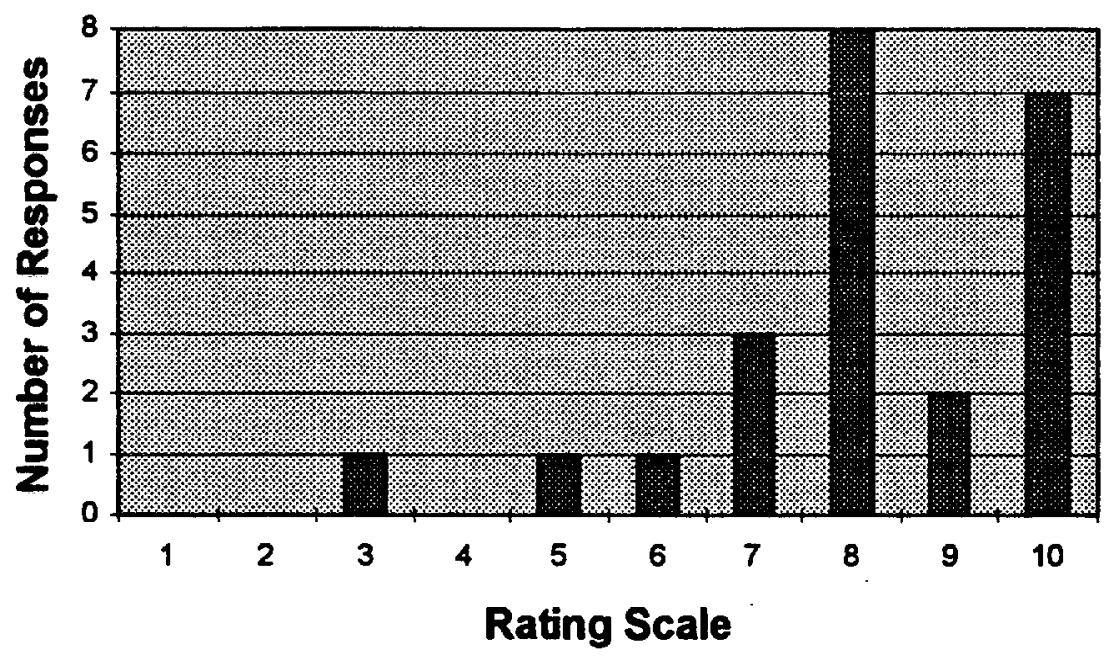

NIST would like to work closely with all sectors of the appearance industry. On a scale of 1 (sorry, no interest) to 10 (when do we start) would your company be interested in such collaboration?

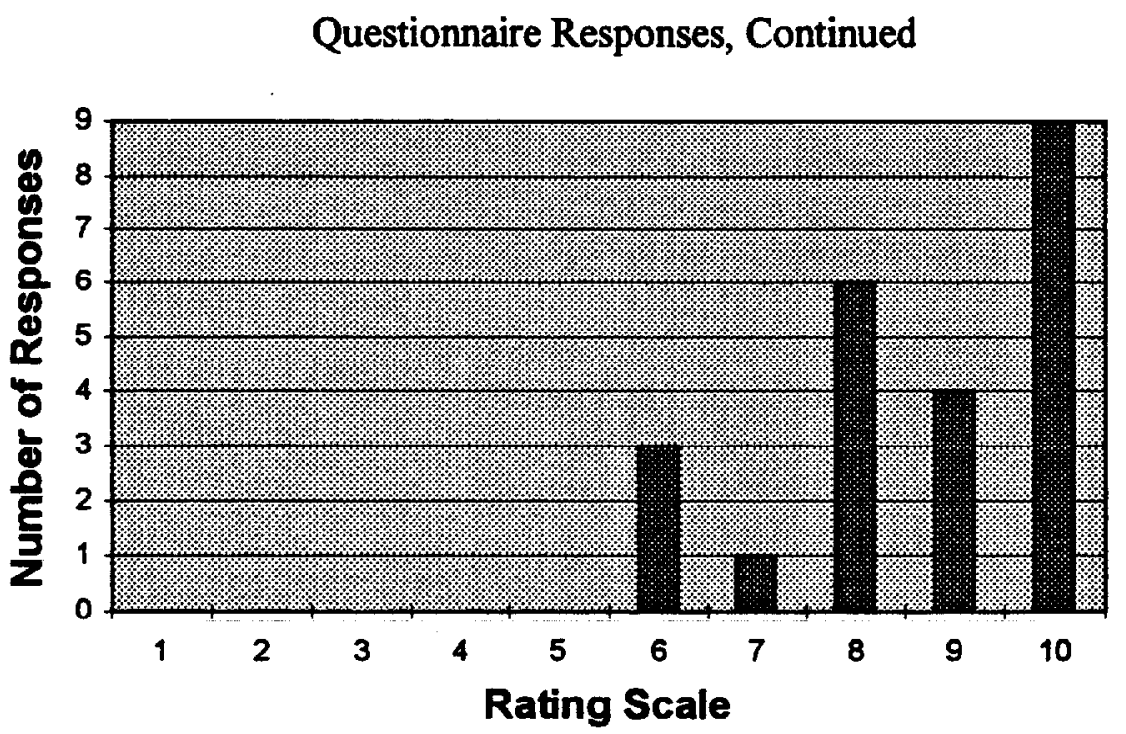

How important would it be for NIST to have a program in appearance measurements from 1 (stay out) to 10 (why did NIST leave)? 
Question. What is the most critical current problem in coating and appearance: technology and what do you foresee to be the most critical problems of the future?

\section{Responses:}

- Developing standard measurements procedures or systems that meet needs of both suppliers and users

- For coatings industry, accurate instrumental characterization of metallic and pearlescent pigmented coatings

- Improved methods of predicting appearance of metallic and pearlescent coatings from formulation parameters and related improved procedures for adjusting appearance

- Long-term aging studies and relationships with material characterization

- Characterization of CRT/Flat panel displays and other radiometric-type measurements

- Lack of standard reference materials

- Finding and demonstrating physical measurements of paint quality that correlate with customer opinions and expectations

- Standard reference materials and procedures for BRDF

- Accurate color and gloss measurements on textured surfaces

- Process modeling (molding, painting, etc.) to relate the effects of process parameters to appearance properties (texture color, gloss, etc.)

- Effective differentiation of graphics and background for contrast ratio, color

- Characterizing daytime reflected and nighttime emitted color and appearance of automotive interiors, e.g., the instrument panel

- Definition of appearance parameters and how to measure them and finally how to combine them into an accepted model

- BRDF modeling only seems as good as your $3 \mathrm{D}$ model of a surface. $3 \mathrm{D}$ modeling is a major problem.

- Availability of measurement equipment

- Determining what data are important to human visual observation and filtering out the data that are not needed

- Gonio-spectro-spatio meter

- Appearance measurements that correlate with human perception; also need measurements that can be used for diagnostic purposes in problem solving, including the ability to look at the basecoat/clearcoat interface

- Use of multi-geometric color measurement (applicable systems, not full BRDF)

- Interpretation of BRDF data 
Question: What would you like NIST to do in the areas of appearance neasurements, nodeling and rendering?

\section{Responses:}

- Help bring BRDF measurements into usable data for industry

- Move forward with multi-disciplinary project

- Provide standards and work with industry to develop appropriate standards

- Standardize BRDF techniques and unify measurements

- Carry out appearance modeling

- Demonstrate the utility of BRDF and computer rendering of surfaces

- Develop procedures for characterizing periodic textures

- Encourage research in the area of color and gloss measurement to come up with new instruments or methods for more accurate measurements on textured surfaces

- Establish metrics for appearance measurements

- Model human vision

- Supply standard reference materials for appearance

- Develop basic fundamental models for predicting appearance

- Make BRDF relevant to basecoat/clearcoat automotive systems - it needs to be combined/resolved with spatially variable information

- Develop a complete measurement and modeling system that can be adapted to all industries; a thorough definition would enable industry to develop instrumentation that would be widely accepted

- Conduct research primarily measurements of appearance

- Develop models to support increased understanding of relationships between microstructure and appearance 


\section{SUMMARY}

NIST held a workshop on appearance to learn industry's needs for improved methods and models for characterizing appearance and to gain comment on a NIST proposed research plan for a systems approach to advance the science of appearance measurements. Representatives from several universities, government laboratories and industries attended. Industries represented included coatings, automotive, electronic, paper, and aerospace. Attendees participated in an open discussion of the ideas presented.

From the discussion and survey input, it was generally agreed that improvements in appearance measurements and models are required. Some specific needs that were identified included:

1) standard quantitative measurement procedures for characterizing reflectance of materials for which reflectance depends on the direction of viewing, 2) procedures for quantitatively characterizing the textures of coatings, paper, textile and other materials, 3) improved understanding of the relationships between reflectance properties and human perception of appearance, and 4) models to predict appearance and durability of coatings from knowledge of the coating constituents. The lack of adequate reflectance data of coated objects, textiles, papers and other materials for rendering models was also noted.

Based on the mission of NIST (which is to promote U.S. economic growth by working with industry to develop and apply measurements and standards) and its historical strength in fundamental studies and appearance measurements, the workshop participants generally agreed that NIST can play an important role in meeting the needs for fundamental measurements and providing coherence and direction among the diverse interests. The workshop adjourned with many people agreeing to consider becoming a member of a working panel to collaborate with NIST researchers.

\section{REFERENCE}

1. CORM Sixth Report, "Pressing Problems and Projected National Needs in Optical Radiation Measurements," Council for Optical Radiation Measurements, December 1995.

\section{ACKNOWLEDGMENTS}

This workshop could not have been held without the professional contributions of the workshop steering committee, presenters, and participants, and the contributions of the cosponsors. Encouragement and financial support from NIST to hold the workshop were provided by Geoffrey Frohnsdorff, BFRL; Dennis Swyt, MEL; Paul Boggs, ITL; Al Parr, PL; and John Blair, Administration. We gratefully acknowledge Mitchell K. Hobish, Consultant, for preparing the first draft of this report and the support of the NIST Conference Facilities personnel for assisting in organizing the meeting and ensuring that it ran smoothly. 


\title{
APPENDIX A. WORKSHOP PROGRAM
}

\author{
Workshop on Advanced Methods and Models \\ for Appearance of Coatings and Coated Objects
}

NIST GREEN AUDITORIUM, ADMINISTRATION BUILDING, MAY 20, 1996

\section{OBJECTIVES OF WORKSHOP}

1. Assess industries' needs for new appearance measurement methods.

2. Introduce NIST proposed research on advanced scattering and rendering models and photometric measurements.

3. Obtain feedback and, if recommended, establish an industrial panel to collaborate with NIST researchers.

\section{AGENDA}

9:00 a.m. Welcome - Arati Prabhakar, Director, NIST

9:10 a.m. Introduction - Mary McKnight (Building Fire Research Laboratory)

9:15 a.m. Need for Advanced Appearance Measurements

- Factors Contributing to Coating Appearance, Juergen Braun, E.I. DuPont de Nemours \& Co. (retired)

- Appearance Measurements at DuPont: Past, Present and Future, Paul Tannenbaum, Richard Stafford, Arun Prakash, and Peter Jansson, E.I. DuPont de Nemours \& Co.

10:45 a.m. Coffee Break

11:15 a.m. NIST's Proposed Program

- Overview, Jonathan Martin, Building and Fire Research Laboratory

- Simulation Modeling, Fern Hunt, Information Technology Laboratory, and Mike Galler, Building Fire Research Laboratory

- Appearance Measurements, Ambler Thompson, Physics Laboratory

- Surface-Morphology Measurements/Bidirectional Reflectance Distribution Function (BRDF) Modeling, Ted Vorburger, Manufacturing Engineering Laboratory

12:30 p.m. Lunch

1:30 p.m. Discussion and Feedback

2:30 p.m. Action Items for NIST

2:45 p.m. Break

3:00 p.m. Establish Industrial Working Committee (if recommended)

3:20 p.m. Adjourn

3:30 p.m. NIST Laboratory Tours

- Surface Finish - Reference Reflectometer - Simulation/Visualization Bldg. 220/A26 Bldg. 220/A318 Bldg. 225/B131 


\section{APPENDIX B. LIST OF ATTENDEES}

Macedonio M. Anaya

Physicist

Boeing Commercial Airplane Group

P.O. Box 3707, MS\$02-JH

Seattle, WA 98124-2207

(206) 294-0733

(206) 294-0515

anammx00@ccmail.ca.boeing.com

Joseph Andritz

Manager Color \& Quality Application

PPG Industries

151 Colfax Street

Springdale, PA 15144

412-274-3532

x3420

Seth M. Ansell

Hewlett-Packard Company

Vancouver Division

1115 SE 164th Avenue

Vancouver, WA 98683

(360) 212-3834

(360) $212-5620$

Seth_Ansell@vcd.hp.com

Clara Asmail

NIST

MET, A305

Gaithersburg, MD 20899

301-975-2339

P.Yvonne Barnes

NIST

MET, A305

Gaithersburg, MD 20899

301-975-2345

Anne-Marie Begin

Engineer

Delco Electronics

1800 E. Lincoln Road

Kokomo, IN 46904-9005

(317) 451-1809

(317) 451-1787

abegin@mail.delcoelect.com
Bruce Blom

Mead Corporation

Mead Central Research

Eighth and Hickory Streets

P.O. Box 1700

Chillicothe, OH 45601-5700

(614) 772-3689

(614) 772-3595

Bruce_Blom@research.mead.com

Philip Bradfiled

Vice President

Tailored Lighting Inc.

9 Tobey Village Office Partk

Pittsford, NY 14534

716-383-8450

Juergen $\mathrm{H}$. Braun

Pigments and Coatings Technologies

614 Loveville Road, E-1-H

Hockessin, DE 19707-1616

(302) 239-0812

(302) 239-0812 (voice-fax)

jhbr@aol.com

Eric Byrd

Chemist

NIST

Bldg 226/Rm B350

Gaithersburg, MD 20899

301-975-6701

975-990-6891

eric.byrd@nist.gov

Ellen C. Carter

Editor, Color Research \& Application

2509 N. Utah Street

Arlington, VA 22207

(703) 527-6003

escarter@capacess.org

Richard Chen

Physicist

Naval Surface Warfare Center

10901 New Hampshire Ave.

Silver Spring, MD 20903

301-394-3516

$\times 5135$

chenr@oasys.dt.navy.mil 
Kes G. Chesonis

Army Research Laboratory

AMSRL-MA-PE

10115 Duportail Road (116)

Ft. Belvoir, VA 22060-5812

kchesonis@belvoir.army.mil

Brian Czubko

President

Autospect Inc.

4750 Venture $D r$.

Ann Arbor, MI 48108

313-213-1700

c2604

bczubko@aol.com

Bruce S. David

Applications Engineer

WPI

P.O. Box 267

Warner, NH 03278

(603) 456-3111

(603) $456-2498$

Julie Dorsey

Asst. Prof.

MIT

10-421

77 Massachusetts Ave.

Cambridge, MA 02139

617-253-6846

x 9407

dorsey@graphics.lcs.mit.edu

Ken Ellis

Technical Staff Member

Atlantic Aerospace Electronics Corp.

470 Totten Pond Road

Waltham, MA 02154

(617) $890-4200 \times 3246$

(617) 890-0224

ellis@aaec.com

Don Emch

Manager

PPG Industries

3601 J. P. Cole Blvd.

Flint, MI 48505-3963

(810) 342-6074

(810) 767-1911

John Escarsega

Army Research Laboratory

ATTN: AMSRL-MA-PE

10115 Duportail Rd (116)

Fort Belvoir, VA 22060-5812
Edwin M. Extract

President

Environmental Marketing

1555 Wilson Blvd.

Suite 300

Arlington, VA 22209

(703) $875-8643$

Hugh S. Fairman

Hemmendinger Color Laboratory

334 Springbrook Trail

Sparta NJ 07871

201-729-7278

Charles Fenimore

Mathematican

NIST

B343/MET

Gaithersburg, MD 20899

301-975-2428

301-926-3534

fenimore@eeel.nist.gov

Sing-Choong Foo

Graduate Student

Cornell University

580 Rhodes Hall

Program of Computer Graphics

Ithaca, NY 14853

607-255-6705

x0806

sfoo@graphics.comell.edu

James L. Gardner

CSIRO Applied Physics

P.O. Box 218

Lindfield, NSW 2070 Australia

(612) $413-7323$

(612) 413-7200

jlg@dap.csiro.au

William M. Gresho

Sr. Design Engineer

Delco Electronics

Mail Station R231

1800 East Lincoln Road

Kokomo, IN 46904-9005

(317) 451-7939

John Hammond

Project Manager

Xerox Corporation

Building 103-05B

Webster, NY 14580

(716) 422-0694

(716) $422-4797$ 
Jonathan E. Hardis

Physicist

NIST

MET, Room A305

Gaithersburg, MD 20899

(301) 975-2373

(301) 840-8551

jhardis@nist.gov

Jim Herriman

President

ASPEX

536 Broadway

New York, NY 10012

(212) 966-0410

(212) $966-2289$

Joyce Higgins

Quality Control Manager

Spray Lat Corporation

1701 East 1022 Street

Chicago, IL 60633

(312) 6465900 ext 18

(312) 646-1022

Mitchell K. Hobish

Consulting Synthesist

5606 Rockspring Road

Baltimore, MD 21209

410-466-0994

x8530

Robert Horvath

Manager, Mexico Paint Process \&

Facilities

CIMS 4822227

12000 Oakland Avenue

Auburn Hills, MI 48326

(810) 576-2583

(810) 576-2009

Jack Hsia

Chief, Academic Affairs

NIST

101, A505

Gaithersburg, MD 20899

(301) $975-3067$

(301) 975-3530

jackHsai@nist.gov

Fern Hunt

Mathematician

NIST

Gaithersburg, MD 20899

301-975-3887

301-990-4127

hunt@cam.nist.gov
Donald Jones

Senior Research Eng.

PPG Industries

P.O. Box 9

Rosanna Dr.

Allison Park, PA 15101

412-492-5317

$\times 5522$

Orick Kelley

Vice President

American Holographic, Inc.

601 River St.

Fitchburg, MA 01420

508-343-0096

508-348-1864

David F. King

Senior Principal Engineer

Boeing

P.O. Box 58928

Seattle, WA 98138

206-342-5927

James Kirby

VP R\&D Automotive Division

Sherwin-Williams Company

101 Prospect Avenue

Cleveland, $\mathrm{OH} 44115$

Alan Kravetz

Technical Manager

Minolta Corporation

101 Williams Drive

Ramsey, NJ 07446

201-934-5228

201-825-4374

Clarence R. Krueger

Principal Engineer

Polaroid Corp

565 Technology Sq-5

Cambridge, MA 02139

617-386-3737

$\times 3761$

budkrueger@aol.com

Jack A. Ladson

Senior Scientist

BYK-Gardner

2435 Linden Lane

Silver Spring, MD 20910

301-495-7150

301-585-4067 
David J. Land

Research Physicist

Naval Surface Warfare Center

10901 New Hampshire Ave.

Silver Spring, MD 20903

310-394-2256

$\times 5135$

landd@oasys.dt.navy.mil

Hector Lara

Product Line Manager

Photo Research

Optical Metrology Laboratory

9330 DeSoto Avenue

Chatsworth, CA $91311-4926$

818-341-5151

$\times 7070$

Frederick H. Lee

Materials Engineer

Atlas Weathering SVCS Group

17301 Okeechobee Rd.

Miami, FL 33015

305-824-3900

305-362-6276

Robert Lipman

NIST

Bldg 225/A141

Gaithersburg, MD 20899

301-975-3829

301-926-3560

lipman@cam.nist.gov

Charles J. Lloyd

Human Factors Scientist

School of Architecture

Rensselaer Polytechnic Institute

Troy, NY 12180-3590

518-276-8717

518-276-4835

David Lo

Senior Research Chemist

Westvaco

11101 Johns Hopkins Road

Laurel, MD 20723

(301) 497-1342

(301) 497-1309

dklo@westvaco.com

Joy Turner Luke

President

Studio 231

93 Bronson Lane

Sperryville, VA 22740

(540) 987-8386
William F. Lynn

Program Manager

Systems Research Laboratorys

Calspan SRL Corp

2800 Indian Ripple Road

Dayton, OH 45440-3696

(513) 255-3839

(513) 476-4728

lynnwf@ml.wpafb.af.mil

Jonathan Martin

Group Leader

NIST

Bldg 226/Rm B350

Gaithersburg, MD 20899

975-67078

975-990-6891

jonathan.martin@nist.gov

Egon Marx

Physicist

NIST

Gaithersburg, MD 20899

301-975-3498

$301869-0822$

Mary E. McKnight

NIST

Bldg 226, Room B350

Gaithersburg, MD 20899

301-975-6714

301-990-6891

mary.mcknight@nist.gov

Gary W. Meyer

Assoc. Prof.

University of Oregon

Dept of Computer and Information Sci.

Eugene, OR 97403

541-346-4413

$\times 5373$

Wyatt J. Mills

Research Supervisor

E. I. DuPont

3401 Gray's Ferry Avenue

Philadelphia, PA 19146

(215) 339-6523

(215) 339-6087

millswj@sptyv.dnet.dupont.com 
Mike Milone

Research Technician

DuPont Company

P.O. Box 80357

Wilmington, DE 19880

(302) 695-2830

(302) 695-2747

milone@al.esvax.umc.dupont.com

Frank Nanna

Systems Design Engineer

Tricor Systems Inc.

400 River Ridge Drive

Elgin, IL 60123

(847) $742-5542$

(847) $742-5574$

Francis X. O'Donnell

Manager, Automotive Color Research

Sherwin-Williams Company

10909 South Cottage Grove Ave.

Chicago, IL 60628

312-821-2271

$\times 2263$

fxodonnell@sherwin.com

William Ott

Deputy Director

NIST

B160, Physics Laboratory

Gaithersburg, MD 20899

301-975-4203

x3038

william.ott@nist.gov

Jeff Parker

Sr. Research Engineer

Autospect, Inc.

1504 Ravine Side Drive

Houghton, MI 49931

(906) 482-7222

same

jparker@up.net

Thomas Pflaum

University of Waterloo

Computer Science

200 University Avenue

Waterloo Ontario N2L 3G1

(519) 888-4567 x4548

(519) 888-1208

tpflaum@cgl.uwaterloo.ca
Chirstine Piatko

NIST

TECH, B266

Gaithersburg, MD 20899

301-975-6033

christine.piatko@nist.gov

Art Poulos

President

Poulos Technical Service, Inc.

7 Waterbury $\mathrm{Ct}$.

Allentown, NJ 8501

609-259-0501

609-259-5710

photochm@aol.com

Christine Reif

Qulaity Control R\&D Engineer

Reflective Technologies

15 Tudor St.

Cambridge, MA 02139

617-497-6171×6175

Danny C. Rich

Manager of Research

Datacolor International

5 Princess Road

Lawrenceville, NY 08648

609-924-2189

609-895-7461

Gerhard Risler

Vice President of Technology

Kolmorgen Instruments (MacBeth)

Fraunhofer Str. 14

Martinsried, Germany 82152

(int49)89857070

(int49)8985707509

102167,350@Compuserve

Holly Rushmeier

IMB TJ Watson Research Center

30 Saw Mill River Road, H0-D06

Hawthorne, NY 10532

914-784-7252

914-784-5130

holly@watson.ibm.com

Andrew F. Rutkiewic

President

Product Tech. Consultants Inc.

PO Box 2158

Tijeras, NM 87039

505-281-7820

73632.1535@compuserve.com 
Peter Sarman

Materials Engineer

Naval Surface Warfare Center

3A Leggett Circle, Code 642

Annapolis, MD 21402

(410) 293-4993

(410) 293-3848

sarman@metals.dt.navy.mil

Clifford K. Schoff

PPG Industries

PO Box 9

Rosanna Drive

Allison Park, PA 15101

412-487-4500

Wendy C. Shemano

Optical Physicist

Systems Research Laboratorys.

2800 Indian Ripple Road

Dayton, OH 45440

(513) 255-3839

(513) 476-4728

shemannc@ml.wpapb.af.mil

Art Springsteen

Principal Scientist/R\&D Director

Labsphere Inc.

P.O. Box 70

North Sutton, NH 03260

(603) $927-4266$

(603) $927-4694$

arfty1166@aol.com

Richard Stafford

Senior Research Associate

DuPont Company

Experimental Station

E357, PO Box 80357

Wilmington, DE 19880-0357

302-695-2810

302-695-2747

Paul M. Tannenbaum

Research Associate

DuPont Company

E357 218C

Wilmington, DE 19898

(302) 695-4054

(302) 695-2747

tannbapm@al.esvax.umc.dupont.com
Ambler Thompson

NIST

Bldg 220/Rm A305

Gaithersburg, MD 20899

301-975-2333

301-840-8551

ambler@enh.nist.gov

Jane Tong

Research Engineer

Westvaco

11101 Johns Hopkins Road

Laurel, MD 20723

(301) 457-7327

jxtong@westvaco.com

Theodore Vorburger

Group Leader

NIST

Bldg 220/Rm A117

Gaithersburg, MD 20899

301-975-3493

301-869-0822

theodore.vorburger@nist.gov

Bruce Walter

Cornell University

607-255-6704

William L. Weber

Optical Engineering Manager

Macbeth

405 Little Britain Rd.

New Windsor, NY 12533

914-565-7660

914-565-0633

willLweber@aol.com

Mary Ellen Zuyus

Director, Technical Services

Hunter Lab/The Color Management Co.

11491 Sunset Hills Road

Reston, VA 22090

(703) $471-6870$

(703) $471-4237$ 